\title{
Study on Visual Style of Twist Silk Knitted Fabrics
}

\author{
Yuan Fang, Ya-qun Zhang \\ Department of Textile Engineering, College of Textile \\ and Materials, Zhejiang Sci-Tech University \\ Hangzhou, China \\ fyuan123@126.com,zyq3951@126.com
}

\author{
Cai-ying Lou \\ Zhejiang textile testing \& research institute \\ Hangzhou, China \\ cttc_zj@163.com
}

\begin{abstract}
The relationship between the twist and the visual style of the silk knitted fabric was studied by testing fabric related parameters. The effect of the twist on fabric dropping property was also investigated. Meanwhile the grey clustering analysis method was applied to evaluate fabric visual style. The results showed that with the increase of the yarn twist, the draping property became undesirable. The fabrics knitted with twistless yarn and low-twist yarn showed the best properties on glossiness and drapability. The fabrics knitted with mediumtwist yarn or high-twist yarn showed moderate glossiness and drapability, and the fabrics knitted with hard-twist yarn show weak glossiness and were stiff.
\end{abstract}

Keywords-Twist silk, Knitted fabrics, Visual style, Grey clustering analysis.

\section{INTRODUCTION}

Silk knitted fabric is loved by numerous people because of its elegant appearance, bright colors and smooth texture. Generally, people know silk fabrics by visual sense and tactile sense. This psychological reaction which is produced by fabric physical stimulation acting on people sense organ is fabric style. The previous researches were mainly on the tactile style. There is little research on the analysis of fabric visual style which is related with fabric printing graphics and colors, fabric glossiness, weave and draping property. Traditionally, fabric glossiness and draping property are called fabric visual style [1,2]. In this paper, some parameters which are related with the glossiness and dropping property of the silk knitted fabrics with different weave and twist were tested. Besides, the grey clustering analysis method was applied to evaluate the visual style of the fabrics.

\section{EXPERIMENTAL}

\subsection{Preparation of the Samples}

In order to eliminate the influence of dyes and get a more reliable result during the research on the relationship between the twist and the visual style, the fabrics made of $100 \%$ silk before dyeing were taken to be tested. The parameters of test samples were shown in Table1. Three of them were selected to take the SEM photos which were shown in the Fig. 1.

\begin{tabular}{|c|c|c|c|c|c|c|}
\hline Samples & $\begin{array}{l}\text { Filament } \\
\text { twist/(t/m) }\end{array}$ & $\begin{array}{l}\text { Yarn linear } \\
\text { density/tex }\end{array}$ & $\begin{array}{l}\text { Square meters } \\
\text { grams }\left(\mathrm{g} / \mathrm{m}^{2}\right)\end{array}$ & $\begin{array}{c}\text { Longitudinal } \\
\text { density/(lateral } \\
\text { line } \cdot(5 \mathrm{~cm})^{-1}\end{array}$ & $\begin{array}{c}\text { Lateral } \\
\text { density/(Longitudi } \\
\text { nal line } \bullet(5 \mathrm{~cm})^{-1} \\
\end{array}$ & Structure \\
\hline $1 \#$ & 0 & $3.8 \times 4$ & 135 & 101 & 87 & Plain \\
\hline $2 \#$ & 0 & $3.3 \times 4$ & 128 & 85 & 78 & Interlock \\
\hline $3 \#$ & 569 & $5.4 \times 3$ & 130 & 95 & 79 & Plain \\
\hline $4 \#$ & 623 & $5.5 \times 3$ & 142 & 87 & 82 & Interlock \\
\hline $5 \#$ & 1215 & $5.2 \times 3$ & 138 & 98 & 80 & Plain \\
\hline $6 \#$ & 1795 & $3.8 \times 4$ & 146 & 90 & 85 & Interlock \\
\hline $7 \#$ & 2205 & $3.5 \times 4$ & 139 & 97 & 86 & Plain \\
\hline $8 \#$ & 2110 & $3.3 \times 4$ & 145 & 94 & 83 & Interlock \\
\hline
\end{tabular}




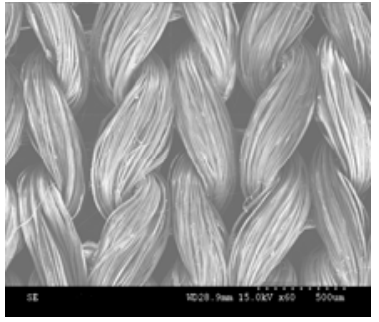

(a) $0 \mathrm{t} / \mathrm{m}$ Plain

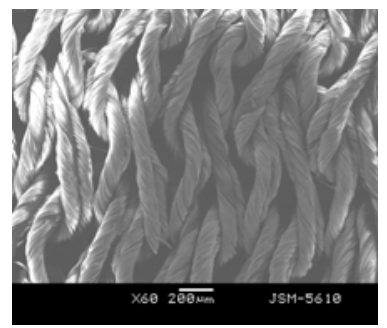

(c) $2205 \mathrm{t} / \mathrm{m}$ Plain

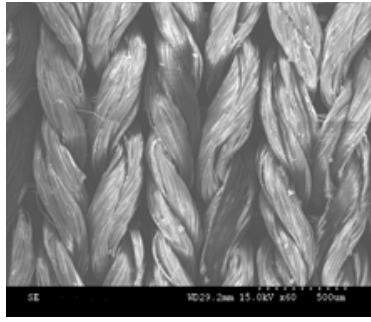

(b) $569 \mathrm{t} / \mathrm{m}$ Plain

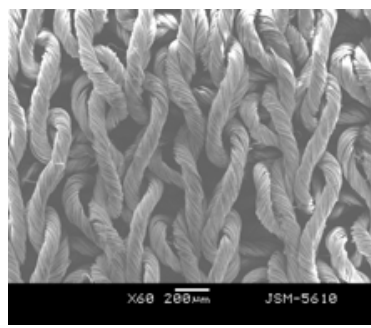

(d) $2110 \mathrm{t} / \mathrm{m}$ Interlock
Fig. 1 The electronic scanning photo of the fabrics with different twist

\subsection{Test Methods and Results}

\subsubsection{The test of glossiness}

The test of glossiness was done in standard atmospheric condition using the M524 glossiness tester, according to FZ/T01097-2006 of "Determination of fabric glossiness". The parameters related with the glossiness in this test included regular reflection light $G_{S}$ and diffuse reflection light $G_{R}$. Meanwhile the gloss of the fabric $G_{C}$, also called contrast gloss, was calculated by the following equation.

$$
G_{C}=\frac{G_{S}}{\sqrt{G_{S}-G_{R}}}
$$

\subsubsection{The test of draping property}

The test of drapability was done in standard atmospheric condition using the YG811 draping tester according to GB/T 23329-2009 of "Determination of fabric drapability ”

The test of bending behavior was done in standard atmospheric condition with the SDL stiffness tester according to GB/T 18318.1-2009 of "Determination of bending behavior - Part 1: Incline method" . 2.2.3 The results of the test Table 2 The test data of fabric glossiness and draping property

\begin{tabular}{|c|c|c|c|c|c|c|}
\hline \multirow[b]{2}{*}{ Samples } & \multicolumn{3}{|c|}{ glossiness } & \multicolumn{3}{|c|}{ Draping property } \\
\hline & $\begin{array}{l}\text { regular reflection } \\
\text { light } \mathrm{G}_{\mathrm{S}} / \%\end{array}$ & $\begin{array}{c}\text { diffuse } \\
\text { reflection light } \\
\mathrm{G}_{\mathrm{R}} / \%\end{array}$ & $\begin{array}{l}\text { contrast gloss } \mathrm{G}_{\mathrm{C}} / \\
\left(\%^{1 / 2}\right)\end{array}$ & $\begin{array}{c}\text { Drape } \\
\text { coefficient/\% }\end{array}$ & $\begin{array}{l}\text { Bending } \\
\text { length/cm }\end{array}$ & $\begin{array}{l}\text { bending stiffness/ } \\
\mathrm{mN} \cdot \mathrm{cm})\end{array}$ \\
\hline $1 \#$ & 75 & 37 & 12.17 & 8 & 0.95 & 0.075 \\
\hline $2 \#$ & 71 & 40 & 12.72 & 8 & 1.00 & 0.089 \\
\hline 3\# & 58 & 66 & 20.29 & 10 & 1.01 & 0.112 \\
\hline $4 \#$ & 59 & 65 & 24.08 & 12 & 1.05 & 0.128 \\
\hline $5 \#$ & 49 & 70 & 10.70 & 17 & 1.15 & 0.216 \\
\hline $6 \#$ & 47 & 74 & 9.04 & 19 & 1.21 & 0.346 \\
\hline $7 \#$ & 42 & 80 & 6.82 & 20 & 1.3 & 0.306 \\
\hline $8 \#$ & 43 & 77 & 7.38 & 21 & 1.32 & 0.389 \\
\hline
\end{tabular}

reached the yarn surface, more regular reflection light was

\section{THE ANALYSIS OF EXPERIMENTAL RESULTS}

\subsection{Analysis of the Glossiness Test Results}

The relationship between yarn twist and fabric glossiness was obtained as shown in Fig. 2. The fitting curve of the regular reflection light was $\mathrm{Y}=0.0164 \mathrm{X}+46.140$ and the correlation coefficient was 0.8160 . The fitting curve of the diffuse reflection light was $Y=-0.0134 X+69.746$ and the correlation coefficient was 0.9275 . The fitting curve of the contrast gloss was $\mathrm{Y}=-6.3 \mathrm{E}-6 \mathrm{X} 2+0.0097 \mathrm{X}+14.155$ and the correlation coefficient was 0.6349. From Fig. 2, we could find that with the increase of the yarn twist, the intensity of the fabrics regular reflection light was gradually weakened, while the intensity of the diffuse reflection light was gradually increased. The contrast gloss achieved its maximum value when the intensity difference between the regular reflection light and the diffuse reflection light reached minimum value. The fiber in twistless yarn was parallel to the axis of the yarn. When the parallel light beam produced. While the fiber in twisted yarn was inclined, the reflection light on the yarn surface was scattered. The more twist the yarn taken, the greater incline of the fiber would be, and the scattering would also become more severe. So the maximum contrast gloss was obtained when the intensity difference between the regular reflection light and the diffuse reflection light became minimum according to the Eq. 1. At this time, the total amount of light intensity is relatively high. 


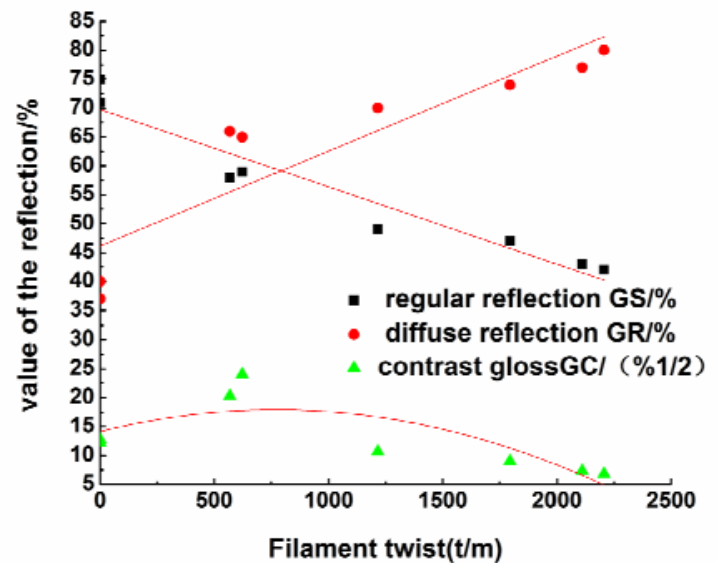

Fig. 2 The relationship between yarn twist and fabric Glossiness

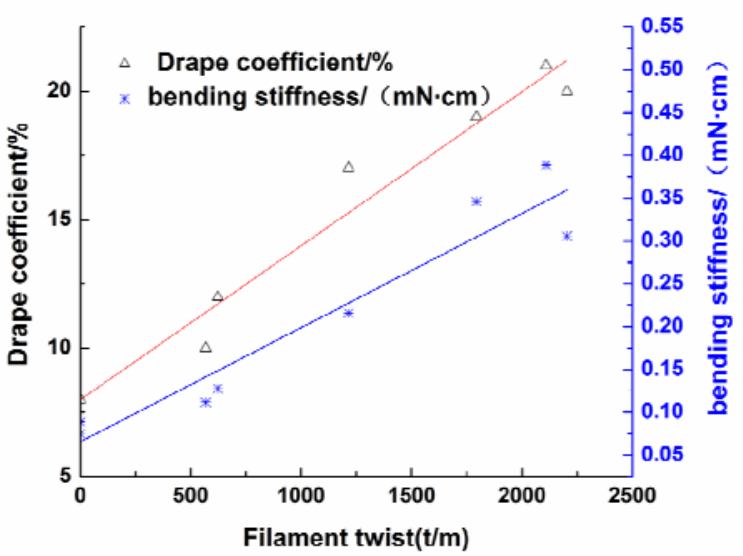

Fig. 3 The relationship between yarn twist and fabric draping property

\subsection{Analysis of the Draping Property Test Results}

The relationship between the fabric draping property and the yarn twist was shown in the Fig. 3. The fitting curve of the drapability was $\mathrm{Y}=0.0060 \mathrm{X}+7.9942$ and the correlation coefficient was 0.9682 . The fitting curve of bending stiffness was $\mathrm{Y}=0.0001 \mathrm{X}+0.0657$ and the correlation coefficient was 0.9229. From Fig. 3, it could be observed that with the increase of the yarn twist the value of fabric drape coefficient and bending stiffness both increased. This was because when the yarn was twisted, the centripetal force acted on the silk in the yarn would be enhanced. Then the entanglement force and the friction force among silk were enhanced. Therefore the yarn stiffness was increased and the fabric drapability was weakened.

\subsection{Selection of Research Method}

Table 2 showed that the fabrics with different weave and twisted yarn had different performances in the tests of glossiness and draping property. It was hard to evaluate the visual style of the fabrics through the data in the table. Mathematical methods were used in some literatures [6-8] to analyze the test data. In this paper grey clustering analysis was employed to classify the visual style of the silk knitted fabrics.

\subsection{Processing of the Data}

\subsubsection{The establishment of clustering whitenizati-on number matrix}

Eight samples in table 2 were taken as the object of grey clustering analysis and the six performance parameters were labeled as clustering index $\operatorname{Mj}(j=1,2,3,4,5,6)$. In this analysis processing, the fabric comprehensive performance was divided into three grey classes. The fabric performance, both good in glossiness and draping property, was labeled as k1. The fabric performance, both moderate in glossiness and draping property, was labeled as k2. The fabric performance, weak in glossiness and stiff was labeled as k3.

The clustering whitenization number matrix could be obtained by mean treatment for the data in table 2. The Eq. 2 below was used in this processing.

$$
(x)_{n \times m}=\left[\begin{array}{llllll}
1.35 & 0.58 & 0.94 & 0.56 & 0.84 & 0.36 \\
1.28 & 0.63 & 0.99 & 0.56 & 0.89 & 0.43 \\
1.05 & 1.04 & 1.57 & 0.69 & 0.90 & 0.54 \\
1.06 & 1.02 & 1.87 & 0.83 & 0.93 & 0.62 \\
0.88 & 1.10 & 0.83 & 1.18 & 1.02 & 1.04 \\
0.85 & 1.16 & 0.70 & 1.32 & 1.07 & 1.67 \\
0.76 & 1.26 & 0.53 & 1.39 & 1.15 & 1.47 \\
0.77 & 1.21 & 0.57 & 1.46 & 1.20 & 1.87
\end{array}\right]
$$

4.2.2 The determination about Whitenization interval of grey class

The interval of grey class $(\mathrm{k} 1, \mathrm{k} 2, \mathrm{k} 3)$ was define according to clustering index $\operatorname{Mj}(j=1,2,3,4,5,6)$. To get better visual style, bigger clustering indexes which reflected fabric glossiness, including the regular reflection light, diffuse reflection light and contrast gloss, were wanted. On the contrary, smaller clustering indexes, including drape coefficient, bending length and bending stiffness were prefered. Meanwhile the Whitenization interval could be determined with dimensionless mean value by the professional knowledge. The result was shown in table 3.

\section{COMPREHENSIVE EVALUATION OF THE FABRIC VISUAL STYLE}

Table 3 Grey clustering interva

\begin{tabular}{ccccc}
\hline Clustering index & $Q_{k 1}($ Good interval ) & $Q_{k 2}$ & (Medium interval ) & $Q_{k 3}$ \\
\hline M1 & {$[1.01, \infty)$} & {$[1-\varepsilon, 1+\varepsilon]$} & $(0,0.80]$
\end{tabular}




\begin{tabular}{lrrr} 
M2 & {$[1.15, \infty)$} & {$[1-\varepsilon, 1+\varepsilon]$} & $(0,0.80]$ \\
M3 & {$[1.50, \infty)$} & {$[1-\varepsilon, 1+\varepsilon]$} & $(0,0.75]$ \\
M4 & $(0,0.90]$ & {$[1-\varepsilon, 1+\varepsilon]$} & {$[1.35, \infty)$} \\
M5 & $(0,0.95]$ & {$[1-\varepsilon, 1+\varepsilon]$} & {$[1.10, \infty)$} \\
M6 & $(0,0.80]$ & {$[1-\varepsilon, 1+\varepsilon]$} & {$[1.50, \infty)$} \\
\hline
\end{tabular}

4.2.3 The determination of Whitenization weight function

Based on the clustering index $\mathrm{Mj}$ and the typical category $\mathrm{k}$, the Whitenization weight function $f_{j}^{k}\left(x_{i j}\right)$ was defined. The method of extended value was applied in the paper, which was shown as following [8]:

a) If visual style was both good in glossiness and drapability, the Whitenization weight function was shown as following:

$$
f_{j}^{k}\left(x_{i j}\right)=\frac{x_{i j}}{Q_{k 1 \text { min }}}
$$

b) If visual style was moderate in glossiness and drapability, the Whitenization weight function was shown as following:

$$
\left\{\begin{array}{l}
f_{j}^{k}\left(x_{i j}\right)=\frac{Q_{k 1 \min }}{x_{i j}}\left(x_{i j} \text { tends to the good grey number }\right) \\
f_{j}^{k}\left(x_{i j}\right)=\frac{x_{i j}}{Q_{k 3 \max }}\left(x_{i j} \text { tends to the bad grey number }\right)
\end{array}\right.
$$

c) If visual style was undesirable in glossiness and drapability, the Whitenization weight function was shown as following:

$$
f_{j}^{k}\left(x_{i j}\right)=\frac{Q_{k 3 \max }}{x_{i j}}
$$

If the smaller dimensionless value of a clustering index meant better visual style, the numerator and the denominator of the formula change their position, as well as the upper limit value and the lower limit value.

4.2.4 The determination of calibration clustering weight

To find the calibration clustering weight the $\lambda_{j}^{k}$ was defined as the boundary value of the index $\mathrm{j}$ and subclass $\mathrm{k}$. Then according to the Eq. 6 , grey number matrix of the clustering weight could be obtained.

$$
\eta_{j}^{k}=\frac{\lambda_{j}^{k}}{\sum_{j=1}^{m} \lambda_{j}^{k}}
$$

$$
\eta_{j}^{k}=\left[\begin{array}{ccc}
0.16 & 0.17 & 0.13 \\
0.18 & 0.17 & 0.13 \\
0.24 & 0.17 & 0.12 \\
0.14 & 0.17 & 0.21 \\
0.15 & 0.17 & 0.17 \\
0.12 & 0.17 & 0.24
\end{array}\right]
$$

\subsubsection{The calculation of grey clustering coefficient}

For the matrix of whitenization number $\left\lfloor x_{i j}\right\rfloor_{n \times m}$, the grey clustering coefficient which the object i belonged to the grey class $\mathrm{k}$ could be calculated according to the Eq. 7 based on the whitenization weight function and the weight value.

$$
\sigma_{i}^{k}=\sum_{j=1}^{m} f_{i j}^{k}\left(x_{i j}\right) \cdot \eta_{j}^{k}
$$

\subsection{Comprehensive Evaluation of the Visual Style}

The matrix above had 3 columns which reflected the fabric visual style. The first column meant the fabric with good glossiness and draping property, the second column meant the fabric with moderate glossiness and draping property and the third column meant the fabrics with weak glossiness and bad draping property. While the category of fabric visual style was decided by the maximum number in each line, According to the calculated results, the following conclusions could be obtained:

1)The samples with both good glossiness and draping property were $1 \#, 2 \#, 3 \#$ and $4 \#$.

2)The samples with moderate glossiness and draping property were $5 \#$ and $6 \#$.

3)The samples with bad glossiness and draping property were $7 \#$ and $8 \#$.

4)Two samples knitted with almost equal twist, such as $1 \#-2 \#, 3 \#-4 \#$ and $7 \#-8 \#$, had different index value. It could be obtained that the value of the plain knitted fabric was bigger than that of the interlock knitted fabric, which showed that compared with interlock stitch, plain stitch could express category characteristics of visual style better.

\section{SUMMARY}

1) The paper investigated the visual style of the fabrics which were knitted with different twist yarn and weave by the experimental research and grey clustering analysis method. The experimental results showed that the fabrics knitted with twistless yarn and low-twist yarn had the best glossiness and drapability, The fabrics knitted with mediumtwist yarn and high-twist yarn had moderate glossiness and drapability. While the fabrics knitted with hard-twist yarn showed weak glossiness and were stiff. 
2) With the increase of the yarn twist, the intensity of the fabric regular reflection light was gradually weakened while the intensity of the diffuse reflection light was gradually increased. The contrast gloss achieved its maximum value for the fabric knitted with yarn twist $600 \mathrm{t} / \mathrm{m}$.

3) For the fabrics knitted with the yarn which had equal twist, plain stitch could express the category characteristics of visual style better compared with the interlock stitch.

\section{REFERENCES}

[1] Zhang $\mathrm{H} \mathrm{Q}$, Liu H. The visual style of garment fabrics [J] Journal of Textile Research, 2003, 24(3):34-46.

[2] Sun Y, Guo J C, Yang J Z. Study on the visual style of worsted fabrics [J]. Wool Textile Journal, 2008, 12:37-40.
[3] Yang J Z. Luster and structure of optim fiber and its blended fabrics [J].Journal of Textile Research, 2007, 28(2):17-20.

[4] Liu S N. Study on the relationship between the luster of woven fabric and its specification factors [D], Zhejiang:Department of Textile Engineering in Zhejiang SciTech University.

[5] Yu W D, Chu C Y. Textile physics [M]. Shanghai: The Publishing House of Donghua University, 2009.

[6] Zhou R, Yang M X, Liu J. Comprehensive evaluation of properties of new regenerated cellulose fiber yarns [J]. Journal of Textile Research, 2013, 34(2):35-39.

[7] Zhu C Q.Grey prediction modeling via grey relational weighting [J].The Journal of Grey System, 2001, 13(3);255258.

[8] Wang X Q. Application of Fuzzy to Textile Industry [M], Hongkong:The Publishing House of Kaiyi,1992. 